\title{
MODELLING OF VISIBILITY OF OIL DISPERSED IN THE SEA WATER COLUMN
}

\author{
Włodzimierz Freda, Zbigniew Otremba \\ Gdynia Maritime University, Faculty of Marine Engineering \\ Department of Physics \\ Morska Street 81-87, 81-225 Gdynia, Poland \\ tel.:+48586901669,fax: +48586206701 \\ e-mail:wfreda@am.gdynia.pl,zotremba@am.gdynia.pl
}

\begin{abstract}
Oil pollution in marine environment is a serious threat both to a variety of animals living in it and the people who benefit from this wealth. These impurities may occur in the depths of the sea as a result of discharges from ships, naval disasters, failures of underwater systems of oil extraction and transportation as well as polluted inflows from the land. The pollutions may be present on the surface in the form of oil layers or films that can be readily observed remotely. But they may also arise in the form of an emulsion of oil beneath the surface of the water. In this case the oil contamination detection is difficult.

In this paper we consider the impact of underwater oil emulsion layer $(5 \mathrm{~m})$ on the property which is measured remotely - remote sensing reflectance $R_{S R}$. The $R_{S R}$ values were calculated using the Monte Carlo method for the Inherent Optical Properties measured in the Gulf of Mexico where the Deepwater Horizon oil spill occurred between late April and mid July 2010. Influence of the depth at which the layer of emulsion exists - on visibility of "oil-cloud" is evidenced. In the studied case the observed contrast of oiled area is negative and reaches zero for the depth exceeding $20 \mathrm{~m}$.
\end{abstract}

Keywords: seawater pollution, oil emulsion, photon trace simulation, light field reconstruction, remote sensing

\section{Introduction}

Pollution of the marine environment pose a threat both to a variety of organisms living in the environment and indirectly to the people who benefit from the diversity of organisms by fishery or tourism. The most common type of impurities are oil pollutions. They may appear in the depths of the sea as a result of discharges from ships, naval disasters, failures of underwater systems of oil extraction and transportation as well as polluted inflows from the land. The pollutions may be present on the surface in the form of oil layers or films that can be readily observed remotely. But they may also arise in the form of an emulsion of oil beneath the surface of the water. In this case the detection of oil contamination is difficult.

Detection of oil pollution in the marine environment can be effective when it is done remotely from the decks of aircraft or satellites. In small basins or along the shoreline the active remote sensing can be used. It involves recording the light scattered and reflected in the environment that is derived from an artificial source of light - a powerful laser. Active remote sensing devices are called lidar (name was originally an acronym of Light Detection and Ranging). Solutions of this type have a very limited range. For the large areas of the sea it is necessary to use the passive remote sensing. That is the method in which the sunlight scattered in environment is recorded.

Active remote sensing takes information from time dependent depolarization [2] or single wavelength induced fluorescence $[4,5]$. In contrast the passive remote sensing, because of unpolarised source of light, bases on spectral information received from environment. In the Baltic Sea region the remote sensing is actively developed by a group cantered on the SatBałtyk project $[13,14]$. 


\section{Methods}

The results presented in this article are based on light field modeling using Monte Carlo method. This algorithm takes into account all phenomena associated with the transmission of radiation in the atmosphere-sea system. Analogous approach like in this paper were applied by Piskozub et al. (2001) [12], Bogucki et al. (2007) [1] and lately by Hieronimi (2013) [8]. The input data in the Monte Carlo algorithm are so called the Inherent Optical Properties (IOPs) of air, water and marine pollution. They are the absorption coefficients, scattering coefficients and the phase functions that describe angular distribution of scattered light. Defining the above mentioned quantities requires to remind the term of radiance $L$ - which is the value describing the quantity of radiation within define small range of wavelengths that is emitted from the surface and falls within a given small solid angle from a specified direction. Hence its unit is watts per steradian per cubic meter. Decrease of the radiance along the propagation path $r$ of the light beam is caused both by absorption and scattering:

$$
\frac{L(\lambda, r)}{L(\lambda, r=0)}=e^{-[a(\lambda)+b(\lambda)] \cdot r},
$$

where:

$a(\lambda)$ - spectral absorption coefficient,

$b(\lambda)$ - spectral scattering coefficient.

Absorption means a conversion of light energy into other form like chemical thermal or its reemission in different wavelength. While scattering is change of direction of propagating light. Description of light scattering requires additional angular distribution. It can be defined in form of Volume Scattering Function (VSF):

$$
V S F(\lambda, \theta, \phi)=\frac{d I(\lambda, \theta, \phi)}{E(\lambda) \cdot d V},
$$

where:

$d I(\lambda, \theta, \phi)$ - intensity of light scattered into direction $(\theta, \phi)$ from the scattering volume $d V$,

$E(\lambda) \quad-$ spectral irradiance illuminating the volume $d V$.

In southern Baltic area the VSFs were measured rarely. The latest and most current data comes from Freda et al. (2007) [6] and from Freda and Piskozub (2007) [7]. These measurements were made with Ukrainian prototype of Volume Scattering Meter described by Lee and Lewis (2003) [9].

Integration of the VSF over total solid angle gives the scattering coefficient $b$. The angular distribution of scattered light is often described by its relative form i.e. the phase function. The latter is defined as the VSF divided by $b$. The set of values needed to describe the behavior of light beam in the environment are called the Inherent Optical Properties (IOPs).

In addition, the Monte Carlo Algorithm require some environmental inputs such as wind speed values which allow to consider the slopes of sea surface (see Cox and Munk 1954 [3]), angular sun position and relative amount of light that comes from the point light source (sun) and diffusive sky.

The result of modeling is the quantity that describes relative water leaving radiance called Remote Sensing Reflectance $\left(R_{S R}\right)$. The $R_{S R}$ can be measured remotely from the decks of satellites or planes. Its definition is given by equation:

$$
R_{S R}(\lambda, \theta, \phi)=\frac{L_{\uparrow}(\lambda, \theta, \phi)}{E_{\downarrow}(\lambda)},
$$

where:

$L_{\uparrow}(\lambda, \theta, \phi)$ - water leaving spectral radiance in direction $(\theta, \phi)$,

$E_{\downarrow}(\lambda) \quad-$ downwelling spectral irradiance incident on the sea surface.

The $R_{S R}$ values were previously obtained by Otremba (2000) [11] for seawater polluted with surface oil film. 


\section{Results}

Virtual pollution in the form of an oil-water emulsion forming a uniform layer of $5 \mathrm{~m}$ was introduced into the marine environment (see Fig. 1). The oil concentration in the layer is equal to $10 \mathrm{ppm}$, and the optical properties i.e. the phase function shape as well as coefficients of absorption and scattering were calculated using Mie theory (Otremba 2007) [10]. The complex refractive index of light of Romashkino crude oil was taken. IOPs of seawater are derived MODIS measurements over the northeastern Gulf of Mexico where the Deepwater Horizon oil spill occurred between late April and mid July 2010. The absorption coefficients of water and oil were respectively $a_{w}=0.059 \mathrm{~m}^{-1}$, and $a_{o}=2.5 \mathrm{~m}^{-1}$. While the scattering coefficients of water and oil were respectively $b_{w}=0.1975 \mathrm{~m}^{-1}$, and $b_{o}=8.4 \mathrm{~m}^{-1}$. The relative amount of light coming from the sun of 63 per cent and coming from the sky of 27 per cent were taken into calculation.

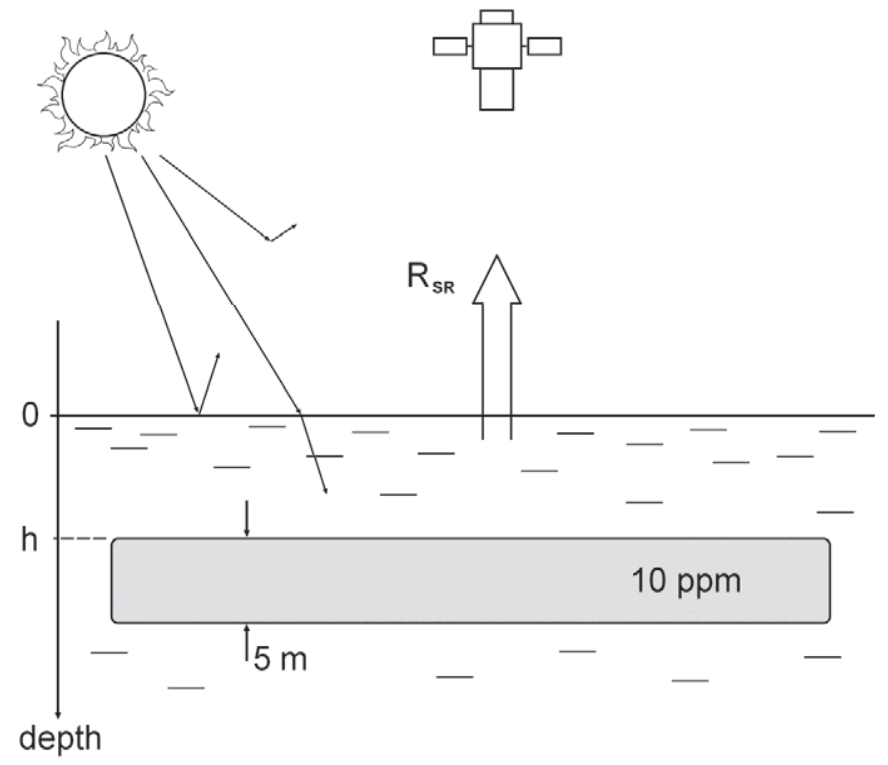

Fig. 1. Explanatory figure showing the studied situation

As a result of Monte Carlo algorithm the values of $R_{S R}$ for various immersion depths $h$ of oil cloud were obtained. These results are shown in the Fig. 2. Values of the reflectance are lower than the $R_{S R}$ value for the case of water free of pollution (value of $\mathrm{B}$ in the Fig. 2). Hence the observed contrast of oiled area is negative. The lowest value of $R_{S R}$ is observed for $\mathrm{h}=0$, i.e. for the case when oil cloud starts from the sea surface (value of A in the Fig. 2). And the deeper immersion depth the higher value of $R_{S R}$. The contrast reaches zero for the depths $h$ exceeding 20 meters.

The variability of remote sensing reflectances $R_{S R}$ seems to be described by expression (4):

$$
R_{S R}=A+(B-A)\left(1-e^{-C \cdot h}\right),
$$

where:

$A$ - the $R_{S R}$ for $h=0 \mathrm{~m}$ (oil pollution layer starts from the surface),

$B$ - the value of $R_{S R}$ (obtained for seawater free of oil pollution),

$C$ - is the characteristic constant value of relation that depend on IOPs of seawater and oil.

In the homogeneous medium the exponential decay describes the variability of radiance on the propagation path (see equation 1) caused by absorption and scattering. Hence we assumed that exponential decay should describe well the variability of water leaving radiance. The supposed equation (4) can be converted into a simple form:

$$
\ln \frac{B-A}{B-R_{S R}}=C \cdot h .
$$




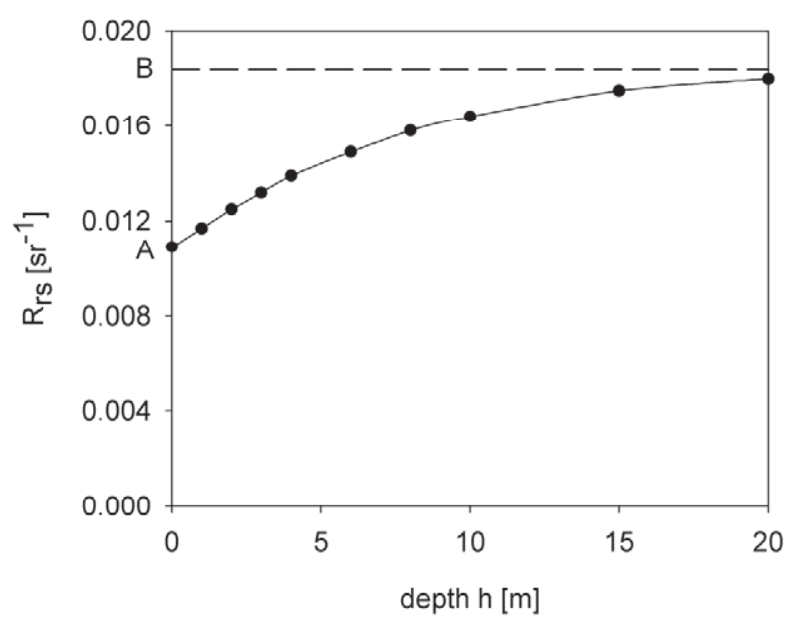

Fig. 2. The $R_{S R}$ values obtained from Monte Carlo radiative transfer algorithm for various immersion depths $h$ of the oil emulsion layer

This form may be plotted in the graph as a linear function. However as one can see in the Fig. 3, the relation of logarithms obtained for modelled $R_{S R}$ slightly differs from linear relation. This means that the equation (4) describes variability of $R_{S R}$ in an approximate way. The approximation is good for small depths only. Obtained reflectances for depths exceeding $5 \mathrm{~m}$ are a bit higher (about 2\%) than it follows from supposed formula (4).

\section{Conclusions}

The paper analyses the impact of the oil emulsion layer placed below sea surface on remote sensing reflectance. The study was prepared with Monte Carlo modeling algorithm. The IOPs of sea water measured in the waters of Gulf of Mexico as well as IOPs of Romashkino oil were used as modeling input data. The obtained results show that the reflectance depends on the immersion depth. Moreover observed contrast of oiled area is negative and reaches zero for depths exceeding 20 meters. The variability of $R_{S R}$ is roughly described by exponential decay.

It is worth mentioning that above described study is exemplary and the method can be applied in $R_{S R}$ analyses for the sea polluted not only with oil substances but also when other alien matter can be found in the sea depths - provided however that the IOPs of these substances are known.

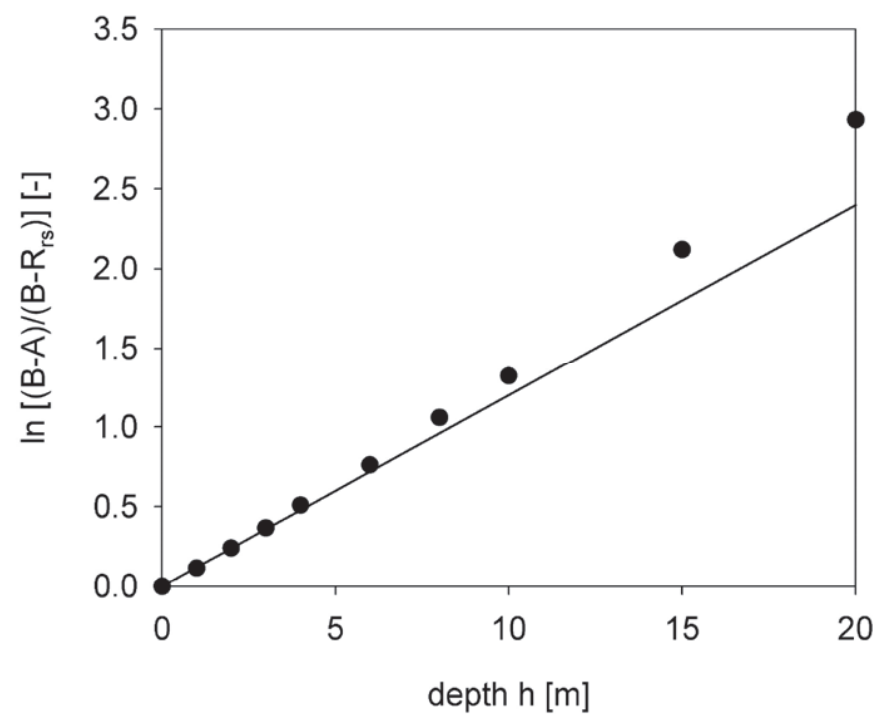

Fig. 3. Logarithms of $(B-A) /\left(B-R_{S R}\right)$ calculated for modelled values of $R_{S R}$ (black points) and linear relation plotted against depth $h$ 


\section{Acknowledgements}

This paper was supported by Gdynia Maritime University statutory researches No. 360/DS/2013.

\section{References}

[1] Bogucki, D. J., Piskozub, J., Carr, M.-E., Spiers, G. D., Monte Carlo simulation of propagation of a short light beam through turbulent oceanic flow, Optics Express Vol. 15, pp. 13988-13996, 2007.

[2] Churnside, J. H., Polarization effects on oceanographic lidar, Optics Express, Vol. 16, pp. 1196-1207, 2008.

[3] Cox, C., Munk, W., Measurement of the Roughness of the Sea Surface from Photographs of the Sun's Glitter, Journal of the Optical Society of America, Vol. 44, pp. 838-850, 1954.

[4] Drozdowska, V., Seasonal and spatial variability of surface seawater fluorescence properties in the Baltic and Nordic Seas: results of lidar experiments, Oceanologia, Vol. 49, pp. 59-69, 2007.

[5] Drozdowska, V., Babichenko, S., Lisin, A., Natural water fluorescence characteristics based on lidar investigations of a surface water layer polluted by an oil film; the Baltic cruise - May 2000, Oceanologia, Vol. 49, pp. 59-69, 2007.

[6] Freda, W., Król, T., Martynov, O. V., Shybanov, E. B., Hapter, R., Measurements of Scattering Function of sea water in Southern Baltic, Eur. Phys. J. ST, Vol. 144, pp. 147-154, 2007.

[7] Freda, W., Piskozub, J., Improved method of Fournier-Forand marine phase function parameterization, Opt. Express, Vol. 15, pp. 12763-12768, 2007.

[8] Hieronimi, M., Monte Carlo code for the study of the dynamic light field at the wavy atmosphere-ocean interface, J. Europ. Opt. Soc. Rap. Public. 8, 13039 pp. 1-11, 2013.

[9] Lee, M.E., Lewis, M.R., A new method for the measurement of the optical volume scattering function in the upper ocean, Journal of Atmospheric and Ocean Technology, Vol. 20, pp. 563-571, 2003.

[10] Otremba, Z., Oil droplets as light absorbents in seawater, Optics Express, Vol. 15, No. 14, pp. 8592-8597, 2007.

[11] Otremba, Z., The impact on the reflectance in VIS of a type of crude oil film floating on the water surface, Optics Express Vol. 7, No. 3, pp. 129-134, 2000.

[12] Piskozub, J., Flatau, P. J., Zaneveld, J. V. R., Monte Carlo study of the scattering error of a quartz reflective absorption tube, Journal of Atmospheric And Oceanic Technology, Vol. 18, pp. 438-445, 2001.

[13] Woźniak, B., Bradtke, K., Darecki, M., Dera, J., Dudzińska-Nowak, J., DzierzbickaGłowacka, L., Ficek, D., Furmańczyk, K., Kowalewski, M., Krężel, A., Majchrowski, R., Ostrowska, M., Paszkuta, M., Stoń-Egiert, J., Stramska, M., Zapadka, T., SatBałtyk - A Baltic environmental satellite remote sensing system - an ongoing project in Poland. Part 1: Assumptions, scope and operating range, Oceanologia, Vol. 53, pp. 897-924, 2011.

[14] Woźniak, B., Bradtke, K., Darecki, M., Dera, J., Dudzińska-Nowak, J., DzierzbickaGłowacka, L., Ficek, D., Furmańczyk, K., Kowalewski, M., Krężel, A., Majchrowski, R., Ostrowska, M., Paszkuta, M., Stoń-Egiert, J., Stramska, M., Zapadka, T., SatBałtyk - A Baltic environmental satellite remote sensing system - an ongoing project in Poland. Part 2: Practical applicability and preliminary results, Oceanologia, Vol. 53, pp. 925-958, 2011. 
